\title{
Automation and Labour in India: Policy Implications of Job Polarisation pre and post COVID-19 crisis
}

\author{
Abishek Nippani \\ Masters of Public Policy, NLSIU
}

\section{INTRODUCTION}

Improvements in information communication systems (ICT) which characterise the $3^{\text {rd }}$ industrial revolution have resulted in a paradigm-shift resulting in it often being dubbed as the $4^{\text {th }}$ industrial wave (Tandem Research 2018). These ICT cover a range of technologies such as artificial intelligence, robotics, platform economies and other technologies, which have been widely adopted to automate labour (all these systems would be collectively referred to as 'automation technology'). 69\% of jobs in India are under threat from automation (World Bank 2016). However, the capability to automate and the choice to automate are not one and the same. The final decision to automate is contingent on a host of other factors revolving around sociocultural norms, cost of labour and so on.

With such automation of labour, a concerning phenomenon has been observed. This phenomenon, known as 'job polarisation', refers to the hollowing out of mid-skill jobs with a relative increase in demand of low- and high-skill jobs. Job polarisation naturally results in wage polarisation and widening of existing inequalities. There is increasing evidence to support the claim that automation results in job polarisation.

However, advocates of automation have claimed that it would follow a Schumpeterian trajectory, and even if jobs are lost or polarised in the short-term, the evolving system will eventually provide newer and better opportunities for labour as a whole. Underlying this claim is the assumption that firms would only adopt automation technologies which bring about substantial increment in productivity and efficiency. However, empirical evidence globally and in India seems to suggest that automation has been following a different trajectory wherein firms have been automating to merely replace labour with capital, without any greater productivity goals.

Moreover, the ongoing health crisis is expected to lead India into recession. Period revolving recessions has been shown to accelerate automation, which results in a jobless recovery. In India, over 12 crore Indians have lost their jobs, and an overwhelming number of these jobs 
are prone to automation. The chief concern is that we must be prepared for a situation wherein the individuals who have lost their jobs due to the health crisis will not be able re-enter the workforce as their jobs can be automated.

This paper seeks to understand the the conceptual framework of job polarisation owing to automation and the underlying analytical framework, how has automation induced job polarisation played out in India, the impact of COVID-19 on this phenomenon and the policy implications that arise from this.

Chapters 2 and 3 discuss the problem of job polarisation as it has existed globally and in India. Chapter 4 seeks to understand how the ongoing health crisis would impact the automation and labour. And lastly, chapter 5 discusses the policy implications that arise in India from this problem.

\section{CONCEPTUAL FRAMEWORK OF JOB POLARISATION}

Job polarisation is a term used to indicate a drop in demand for mid-skill jobs, and a simultaneous increase in demand for high- and low-skill jobs, which results in a 'hollowing out' of mid-skill jobs (Jaimovich and Siu 2018). As structures of the economy change over time, job polarisation can occur due to various factors such as labour supply, education levels within an economy, sociocultural elements, and of most relevance to us - due to automation. Job polarisation owing to automation has been drawing increasing concern. Job polarisation linked to automation has been empirically observed in the USA (Acemoglu and Autor 2011; Jaimovich and Siu 2018); UK, Sweden and other European Countries (Petropoulos 2018); and even in developing countries such as Brazil and Colombia (Kuriakose and Iyer 2018). This confirmation of the worry over automation and job polarisation having been validated, scholars have been attempting to better understand this relationship.

\section{Canonical Method and Task-Based Analysis}

Traditionally, impact of automation on labour had whole occupations (banker, IT professional, etc.) as the unit of analysis, and occupations were ranked as per skill levels (high, medium and low). This method was not able to provide explanations that were required, such as how exactly automation interacts with and affects labour. Acemoglu and Autor (2011) conceptualised an innovative and revolutionary framework to understand how automation interacts with various 
aspects of labour and results in polarisation. Under this framework, jobs are not considered as strictly comprising of a single function or role, as was understood previously. Rather, they are often made of multiple tasks. They termed this a 'task-based model', and hold that tasks are the fundamental units of jobs, and accordingly, every job can be broken down into various tasks to better analyse the effect of automation on them.

Based on their repetitiveness and cyclical nature, tasks are categorised into two broad groups - routine and non-routine tasks. This is further classified into mechanical and cognitive task, based on the complexity of task involved.

The aforementioned studies pertaining to empirical evidence on job polarisation owing to automation have reaffirmed Acemoglu and Autor (2011) findings that automation primarily substitutes routine based jobs. Depending on the tasks which comprise a given job, one can infer the level of skill required. Routine tasks, whether cognitive or manual, both overwhelmingly constitute mid-skill jobs. On the other hand, automation is said to augment the functioning of non-routine jobs, which comprise of low- and high-skill jobs.

Table 1. Occupational typology

\begin{tabular}{|c|c|c|}
\hline Repetitiveness/Complexity & Manual & Cognitive \\
\hline \multirow{2}{*}{ Routine } & Assembly-line & Clerical, \\
& Sales \\
\cline { 2 - 3 } & Middle Skill & Middle-Skill \\
& Substitutive Effect & Substitutive Effect \\
\hline \multirow{2}{*}{ Non-Routine } & Personal services, & Managerial, Creative \\
& Security & High-Skill \\
& Low-Skill & Complementary Effect \\
\cline { 2 - 3 } & Limited Effect & \\
\hline
\end{tabular}

Source: (Kuriakose and Iyer 2018) 
The twin effect of automation substituting routine tasks while simultaneously augmenting nonroutine tasks is what results in 'hollowing out' of mid-skill jobs and leads to job polarisation (Acemoglu and Autor 2011).

\section{JOB POLARISATION IN INDIA}

\section{Economy at a Glance}

In a comprehensive study by (Sarkar 2018), the author uses National Sample Survey Office (NSSO) employment data covering 270 occupations in urban India from the years 1983-84 to 2011-12 to arrive at few key observations. Firstly, she notes that there is a strict distinction between industries that generate output and ones that provide employment, which has had a role in shaping the demand for routine and non-routine jobs. Secondly, post liberalisation, demand of routine tasks has considerably fallen. This has been attributed to the susceptibility of routine tasks to automation.

She also finds wages for low and high skill labour increasing from the 1990 to 2010, while wages for mid skill labour shows a decline after 1999, which signals the drop in relative demand of mid-skill jobs resulting in wage polarisation associated with job polarisation.

Vashisht and Dubey (2018) reaffirm the findings of Sarkar (2017) and further the understanding by stating that the demand of labour skilled in non-routine tasks increased substantially at the turn of the century, with the demand of labour skilled in non-routine cognitive tasks having increased fourfold. They note that with this increase in demand of nonroutine tasks cognitive tasks (which make up high-skill jobs), the share of high-skill workers in the total employment has also increased, furthering wage polarisation.

While these studies broadly highlight how automation has polarised jobs in India, the effects would be better understood if we take a look at the manufacturing sector.

\section{Manufacturing}

Using NSSO employment data from 1993-94 to 2011-12 in the manufacturing sector, Vashist (2017) has found a sharp decline in the share of routine-based occupations in total manufacturing jobs. He then notes that this decline in demand of mid-skill routine jobs has been met with an increase in share of low- and high-skilled workers in the aggregate labour composition. Vashisht (2017:8) states that, 
the share of both skilled- and unskilled-intensive occupations has increased at the cost of middle-level skill-intensive occupations such as machine operators, clerks and craft-related workers. The share of machine operators, clerks and craft-related occupations, which are generally concentrated at the middle of the skill distribution, has come down from 76.5 percent in 1993-94 to 70.2 percent in 2011-12. Their wage share, too, has come down from 70 percent in 1993-94 to 59.4 percent in 2011-12.

He concludes by attributing the polarisation chiefly to automation and adoption of emerging technology that have substituted capital for labour, in line with global trends. This rapid automation has been facilitated by policies of liberalisation, particularly when 100\% FDI was allowed in 1998 (Vashisht and Dubey 2018).

It should be noted that this is based on a model wherein the output remains fixed, since automation does not necessarily bring about greater productivity, and when it does, the gains do not materialise in the short-run. However, Vashist (2017) observes that in the long-run when we let output be variable, technology has a significant positive effect on employment resulting in net gain in employment, while in the short-run jobs are displaced and polarised.

Apart from manufacturing, increasing automation of routine-based jobs has also been observed in the industries of automobiles, pharmaceuticals, IT services, agriculture and food processing and textiles. (ILO 2018a). ${ }^{1}$

\section{Persistence of Routine Tasks}

Despite the foregoing discussion on automation and routine jobs, a development that deviates from job polarisation observed in other economies is that in India, routine jobs have managed to persist at a higher level than expected (Kuriakose and Iyer 2018; Vashisht and Dubey 2018). Though the share of routine task intensive jobs in the aggregate labour has declined by almost 8\% from 1995-2012 (World Bank 2016), on a macroeconomic level, jobs comprising of routine manual tasks such as machine operators and routine cognitive tasks such as call-centres/sales have managed to occupy a share of the total employment above than levels observed in developed countries.

Kuriakose and Iyer (2018) argue that the persistence of routine task intensive jobs in India is due to two reasons, neither of which are directly related to automation or technology. First, due to the increase in supply of educated labour (secondary and tertiary education) has resulted in labour oversupply. This has not only depreciated the wage premium placed on education, but oversupply has pushed educated workforce that would find itself in mid-skill jobs into low-

\footnotetext{
${ }^{1}$ For an updated, quantitative and tasked-based study on the effects of industrial robots on India's industries (albeit predicated on only one form of automation), see Mani (2019).
} 
skill jobs. Thereafter, supply of cheap educated labour has incentivised employers employ well educated labour for routine, otherwise automatable, tasks. Second, Building on Sarkar (2018), the authors state the second reason for the persistence to be the divergence between labourintensive and output generating industries in India. Labour intensive industries such as paper, textiles, etc. continue to overwhelmingly comprise of routine intensive jobs as labour continues to have the competitive edge owing to the abysmally low wages in India.

\section{Social Class and Task Profiles}

It is true that automation has the potential to bring in its wake a plethora of new opportunities ripe for exploitation. People with access to the digital sphere along with capable skills have already been reaping the newfound opportunities that are dynamically evolving with advances in computers and related fields. India is the largest supplier of online labour, accounting for $24 \%$ of the global supply (The iLabour Project 2017). A substantial advancement in automation has been the creation of the platform economy, which acts as a digital marketplace for interested buyers/sellers to transact. This has brought about a revolutionary change in the nature of work. Online labour economy is based on such platform economies (Tandem Research 2018). However, while the sellers/producers are usually self-employed, the term 'selfemployed' holds a different connotation when one refers to a freelancer who has exercised an option to be self-employed as a career move, and Ola/Uber drivers who essentially have no better option.

Aggravating this problem is the finding that jobs comprising of non-routine cognitive tasks (high-skill, high-wages) are largely occupied by socially forward castes (Vashisht and Dubey 2018). On the other hand, routine and non-routine manual task intensive jobs (med- to lowskill) are overwhelmingly comprised of backward classes (ibid.). An explicit example is the case of manual scavenging in India. Firstly, technology to automate this task exists (Tandem Research 2018). Secondly, it is illegal to contract workers to undertake the task of manual scavenging. Despite this, prevalence of caste and other social relations has prevented the automation of this job.

As automation continues to result in substitution of manual task intensive labour with capital and increases relative demand of high-skill cognitive workers, the widening wage gap between high-skill and low- to med-skill workers will exacerbate existing inequalities.

\section{Trends ahead}


Studies have indicated that this phenomenon is expected to rise. $65 \%$ of global IT services and business processing is outsourced to India, jobs predicated on tasks estimated to be completely automated by 2030 (BusinessLine 2018). Moreover, 60\% of the jobs in India's formal employment structures are routine jobs, which are susceptible to automation (ILO 2018b) and a whopping $69 \%$ of jobs in India are under threat from automation (World Bank 2016).

While the caveat stated earlier must be kept in mind - that automation of jobs depends on factors additional to how prone a job is to automation - automation will be increasingly favoured as per current trajectory, and will continue to produce few undesirable consequences.

\section{Market and Socially Desirable Automation}

It is often assumed that firms choose to automate as the same brings in substantial strides in efficiency. This belief also holds that firms therefore only automate, and substitute labour with capital, when the gains in efficiency far outweigh the costs of continuing with labour. Moreover, this substantial increase in efficiency increases the economy's overall productivity, which results in creation of new jobs as economies evolve. Such an understanding is based on Schumpeter's (1943:83) famous words

process of industrial mutation - if I may use that biological term - that incessantly revolutionizes the economic structure from within, incessantly destroying the old one, incessantly creating a new one. This process of Creative Destruction is the essential fact about capitalism

In such a system, though automation may destroy jobs, it will open up new sectors and opportunities which lead to creation of new jobs. This is what Acemoglu and Restrepo (2019) term as the reinstatement effect of automation, wherein the productivity of such technology is so high that displaced labour is reinstated in new forms within the economy.

Implicitly, creation of new employment is contingent on the belief that only automating technologies which possess productivity far greater than labour will be adopted. What happens, then, if firms bring in technology that only substitutes existing labour and does not raise overall productivity? In such a situation, the displacement effect of automation would manifest, resulting in what Keynes (1930) termed as "technological unemployment". Technological unemployment is the redundancy of labour caused by our inability to generate new jobs at a rate faster than rate at which technology substitutes labour.

The real situation is grim. There is increasing evidence to show that firms have been adopting automating technology as a means to merely substitute labour globally (Acemoglu and Restrepo 2020) and in India (Tandem Research 2018). This is corroborated by the fact that 
labour productivity has remained largely stagnant for almost 60 years now (since 1960s), and even more so after liberalisation of the Indian economy (The Wire 2017).

This gives rise to a few important concerns. Firstly, the mere replacement of labour with automation technologies results in a decrease in the share of workers at the original level of overall earnings. Essentially, automation aimed at substituting labour always reduces labour's share in the overall earnings, since the number of workers engaged has declined. Secondly, considering that automation in most probability will bring about at least some marginal improvements (but not so productive as to give rise to enough new opportunities), the increment in earning is now shared between an even smaller section of the society. Scholars have put forth the claim that patterns of automation reflect dominant social interests and adoption of automation technology reinforces and benefits existing power structures (Tandem Research 2018).

The question that next arises is, whether the market is able at all to deliver socially desirable automation technology? Acemoglu and Restrepo (2020) note that when there are multiple competing paths to automation available, the market tends to become parochial and bandwagon on the most dominant path, which is known as the 'technological paradigm'. There is nothing that guides the firms to pursue the 'right' or 'correct' technological paradigm, and considering the dynamic and yet to be understood $4^{\text {th }}$ industrial wave, "our trust in the market mechanism getting it right should be even lower" (Acemoglu and Restrepo 2020:31).

The need for tech progress to be productive enough to create additional jobs is not necessarily an economic need. Rather, it is a social need based on equity before an economic one. Such a need thus does not translate into an economic need for the market, which is now not bothered to invent/adopt mere substituting automation which are marginally more productive than their labour counterparts. This is in line with traditional understanding that the efficient allocation of resources can, and often is, mutually exclusive to distributional concerns or how the pie is shared.

From the foregoing it is clear that automation can have debilitating effects on the existing labour structures. This in itself is not of much concern if the technology adopted manifests productivity which leads to creation of new jobs. However, evidence supports the claim that 
automation is increasingly being adopted to merely displace labour and substitute capital for labour. In such a situation, labour shares will fall. Job polarisation owing to automation in itself results in wage polarisation as well. Therefore, lower labour shares, increasing wage inequality and failure to generate new jobs can have catastrophic effects on vulnerable sections of society.

\section{AUTOMATION POST COVID-19}

Almost all the research and literature relied on up till this point were studies based on trajectories before the COVID-19 health crisis hit the world. The crisis has left millions of people without a job, with an astonishing 122 million Indians having lost their jobs in the month of April alone (The Hindu 2020). Moreover, industries that have been affected by COVID-19 are industries which were considered as susceptible to automation even before the health crisis (CSLF 2020). Adding to this, changes in attitudes and social dynamics which prefer physical distance and reduced human contact could potentially drive up the rate of automation. The aim of this chapter is to highlight the concern that a substantial portion of the labour which was rendered jobless due to the health crisis will discover that their jobs have been automated.

\section{Recession and Jobless Recoveries}

Jaimovich and Siu (2018) set out to study the interplay between job polarisation and jobless recoveries, and their analysis has borne extremely crucial findings. For purposes of clarity, jobless recovery is the phenomenon revolving recessions wherein bouncing back of the economy from a slump does not result in a recovery in aggregate employment levels. Or in other words, though the economy as a whole recovers to pre-recession levels, there is no corresponding recovery in the number of jobs that were lost to the recession.

The authors find that over the last three recessions in the USA, a shocking $88 \%$ of jobs that were lost comprised of routine tasks, indicating that recessions primarily result in deletion of routine-based jobs. Moreover, 'essentially all' of these jobs were thereafter automated, which results in the economy restoring to pre-recession levels without re-absorbing the labour that lost jobs during the recession. They also provide evidence against the notion that automation is a gradual process which unfolds slowly overtime. Rather, they state that automation occurs in fits and starts, with highest rates of automation during economic slumps and downturns. 
They conclude by stating that jobless recoveries are intrinsically linked to job polarisation, since automation of routine mid-skill jobs results in, if not an increase in relative demand of high- and low-skill labour, a hollowing out of mid-skill workers.

\section{COVID-19's Unique Impact on Automation}

The COVID-19 pandemic is projected to only increase the rate of automation globally (Muro 2020) and in India (Livemint 2020). India is also posed to enter recession (BBC 2020). The health crisis will give rise to a range of varied incentives and motivations to go for automation, which will have the effect of further polarising jobs.

1. Business prerogatives; adjusting business operations amidst lockdowns

- Unlike before the crisis, when benefit of automation was valued against cost of labour, the current crisis will give rise to automation demand based on survival imperatives of firms.

○ Lockdowns throughout the world have made firms look at operating without humans.

2. Changes in attitudes and sociocultural norms regarding human contact and physical distance may induce employers to opt for automation.

3. Health concerns over sanitation and physical distancing, from workers and customers

4. Volatility of labour supply in India which has conventionally been considered strictly inelastic. The discontinuation of work by migrant and other workers en masse in midto low-skill jobs has provided employers the impetus to consider automation to this end.

- As industries, especially MSMEs which employ the greatest number of workers, have been facing hardships owing to the unavailability of migrant or other cheap labour, manufacturers are keenly looking at automating their conventional labour based processes.

A report by NASSCOM (2020) titled 'COVID-19: The Tipping Point for Automation' is very telling on its own. The report notes that global and domestic economy has to take unprecedented efforts to recover from this crisis, and on this path, it will adopt wide-scale automation, and automation adoption rates will grow at 'highest-ever rates'. The predictions of this report are in consonance with Jaimovich and Siu (2018), and state that many labour intensive industries which have laid-off workers due to acute shortage in demand, will on the path to recovery opt for automating their labour needs instead of engaging labour. However, 
unlike Jaimovich and Siu (2018), NASSCOM claims that automation will be staggered in its adoption and will be phased up until 2035.

Other projections have also been in-line with Jaimovich and Siu (2018)'s findings. Manufacturers have stated that the time to implement automation technology is 'now', when market demand is low and economy is heading for a downturn. Also, industries that conventionally did not look at automation of labour are increasingly considering automation technology (BusinessLine 2020).

The concern raised at the beginning of this section thus garners validity. The COVID-19 crisis will increase automation in two ways. First relates to the recession which India, and the world at large, is posed to enter. Jaimovich and Siu (2018) have found that jobs lost during recessions are primarily routine based jobs, which are subsequently automated. This results in a jobless recovery of the economy. Secondly, the health crisis will bring about new attitudes and changes in commecial, socio-cultural and health related incentives. Dynamics of business operations, workers' needs and consumers' demands will change, giving way to greater automation.

Perhaps what is the most concerning of all is that post the health crisis, substitution of labour and replacement of humans with atuomation technology will in itself be a valid ground. In this case, the productivity effect - which is responsible for generating new jobs - is no longer a concern.

\section{POLICY IMPLICATIONS}

Job polarisation owing to automation falls within the textbook definition of a wicked problem (Rittel and Webber 1973). It is nearly impossible to definitively describe the policy problem in its entirety, there is no consensus on what approach is considered equitable and it is impractical to label any interventions as optimal.

Yet, something must be done. The foregoing discussion makes it clear that automation can have adverse impact on labour owing to job and resultant wage polarisation. The polarisation of jobs hollows out demand of mid-skill workers while increasing relative demand of high- and low-skill workers. An implication of this that goes unattended is that many rural people in India aspire to occupy mid-skill formal jobs. This aspiration stems from the escape from poverty and upward social mobility that mid-skill jobs present. Even prior to the ongoing COVID-19 health crisis, automation has resulted in job and wage polarisation in India. However, post-crisis, 
studies have indicated that the rate of automation is going to increase due to aspects specifically related to the crisis. On top of this, India is set to enter a recession, which will only further the hollowing out of mid-skill jobs.

If substitution of labour for the sake of replacement picks up momentum, the effects can be catastrophic. The failure of these technologies to bring about substantial increase in productivity will result in technological unemployment of an unprecedented scale.

\section{Principle-based}

This signals towards the need to have pre-emptive safety nets or protective mechanisms in place. To analyse effects as they are unfolding and devise policies is not only next to impossible, but a foolish strategy. We can adopt a principle-based approach, wherein we know the outcome must conform to principles agreed upon. The following two guiding principles are selected:

I. Do not hamper automation, and let the market experiment.

Automation has the potential to bring in substantial improvements in aggregate quality of life and work opportunities. The quest for realising such technology must not be thwarted by restrictive policies stemming from Luddite paranoia.

Hence, market forces should be left to interact freely. To enable market forces to realise the greatest benefits, it is crucial for labour supply to be adequately equipped to withstand changing tides of automation. More specifically, labour must be skilled enough to shift jobs within and between sectors. Such mobility is possible if workers possess skills covering a range of tasks in demand, especially cognitive, both routine and non-routine.

II. Right to decent work; do not plan for mass technological unemployment, but facilitate reinstatement

Work is essential to humans and provides benefits that transcend the individual person it originally concerned. A state of affairs wherein nobody needs to work as technology has taken care of the 'economic problem' - as Keynes predicted 2030 would be - might not be the most desirable outcome.

W. J. Wilson states that "the consequences of high neighbourhood joblessness are more devastating than those of high neighbourhood poverty" (quoted in Brynjolfsson and McAfee 2016). 
Accordingly, policy must give space for automation, but at the same time ensure that the hollowing out of mid-skill jobs (and jobs in general) does not violate labour's right to decent work. This can be achieved by skilling and facilitating mobility, incentivising labour engagement and having a social protection system in place.

Another consideration to keep in mind is that interventions must be wary of making labour more expensive (higher MW, extra contributions to labour funds, etc.) as that would bring down the relative cost of automation.

\section{Imperative 1: Skilling and Labour Mobility}

Oversupply of educated labour in India has resulted in funnelling of mid-skill labour into lowskill jobs (Kuriakose and Iyer 2018). Part of the reason for this rigidity in upward mobility of mid- and low-skill workers is that skilling and other aspects which characterise high-skill workers are acquired from a young age. As highlighted by Vashisht and Dubey (2018) jobs comprised of cognitive and analytical tasks which demand high-skill labour are dominated by socially forward castes. It is a well-known fact the schools which matter the most, i.e. primary and secondary schools, have good schools effectively reserved for economically privileged stratums of the society.

The government has recognised the need to impart skills to place them in a better position in the ruthless market. Ministry of Skill Development and Entrepreneurship has launched various schemes to this end. Pradhan Mantri Kaushal Vikas Yojana (PMKVY), a flagship scheme of the, aims at skilling the youth in industry demanded skills (MSDE a). Skills Acquisition and Knowledge Awareness for Livelihood Promotion also has similar aspirations (MSDE b). Projects $^{2}$ in the past have indicated that attempts at scaling up skilling of the workforce has not been met with increase in labour demand/job creation as expected.

These, and other efforts by the government, though well-intentioned, are not steps in the right direction. A key requirement for workers in the coming years would be the ability to undertake cognitive tasks. Though routine-tasks in general get automated, routine-manual is usually affected worse than its cognitive counterpart.

As alluded to earlier, the acquisition of cognitive and analytical skills is shaped by group inequalities and issues of access to good formal education. In other words, cognitive task

\footnotetext{
${ }^{2}$ Youth training and employment programmes trained over 18 lakh individuals in 2015. However, only 12.4 per cent or 2.23 lakh trainees got actually placed in jobs (Tandem Research).
} 
intensive jobs have usually been more resilient in India, and non-routine cognitive task intensive jobs have benefitted the most in India and throughout the world (Kuriakose and Iyer 2018; Vashisht and Dubey 2018). In general, individuals occupying these mid- to high-level jobs have had access to better formal sources of education, which have nurtured these skills. Therefore, as long as skilling is largely based on ITIs, manual skills and other skills which fall within routine manual and routine cognitive tasks, individuals are being skilled for certain failure, as their skills are not desired by the market.

There is empirical evidence supporting this claim. In 2018, a market labour demand survey showed that machine operators and technical staff (both of which are extensive routine-manual jobs) were part of the top ten jobs in demand by the industry (ManpowerGroup 2020). The 2019 survey of market labour demand showed that the top ten jobs demanded by the industry now all comprise of cognitive tasks. The fall out of routine tasks from 2018 to 2019, according to the report, reflect the rise in automation. The report also claims that share of recruiters who could not find workers with the requisite desired skillsets has only been increasing over the years, and presently, $64 \%$ recruiters cannot find workers with the skills sought after.

It thus becomes important to re-envision skilling and education in general. Various labour competencies are determined by which schools people go at young age, which is highly classcontingent in India. To right this wrong, we need to stop treating education and skills training as they have conventionally been understood. Workers from all spheres will have to keep reand up-skilling throughout their careers as and when disruptive technology keeps emerging. We cannot allow labour to compete solely on privilege of good education received in childhood, competencies have to be developed in individuals that go beyond specific tasks. An example of this is soft-skills training for integrate individuals into hotels and accommodation industry, these skills can be utilised in other jobs as well.

\section{Imperative 2: Social Security}

There is an urgent need for simultaneously devising a social security measure. If labour mobility turns out to be low, it becomes extremely important to have a social safety net which mitigates the adverse impacts of automation on labour. The job polarising effect of automation will result in two ills revolving social security - first, many mid-skill workers are displaced from formal employment structures wherein they received social security benefits; second, the wage polarising effect reduces the dispensable income available to workers, which could result in reduction in income being utilised for health purposes. 
While a universal basic pay, without doubt, is the right way to go (Frey 2020), a more actionable and immediate step is to create portable social security funds to which the government, employer, and employee contributes. The instrument would not cease to exist if the employee changes her job. The new employer would simply make their contribution to her social security. In today's platform economy of 'on-demand' work (Ola, Uber Swiggy, etc.), contractual digital work and alike, workers simultaneously work for multiple employers, while receiving social security benefits from none of them.

Such an instrument would require how many ever employers a worker engages to all provide social security. To avoid confusion and unneeded complications, employers would make contributions based on task or set of tasks performed, instead of continuous periodic payments.

A portable social security instrument of this sort will be able to adjust to the trends observed in labour. Firstly, it will help combat the growing ills of rampant contractualisation of work in India which leaves hundreds of millions without access to employment related social security. Secondly, as is evident, workers have been diversifying employment opportunities. For example, an Ola driver operating with Uber and vice versa.

The role of the State in financing this fund is important as the funding aspect should not burden industry too much. Rather, if the industry considers the costs for engaging labour to be substantial, it would catalyse automation. The Vice Chairman of the Niti Aayog has recognised this responsibility and stated that in developed economies, social security is extensively provided by the State (Livemint 2017). To this end, India should have a labour fund which helps with provident fund, medical costs and so on (ibid.). Other areas for generating funding of this instrument can explored, such as giving individuals the right to be paid whenever their data is utilised for purposes other than they had originally up for. These would require a legaleconomic exploration.

\section{Imperative 3: Labour's Competitive Edge over Automation}

The last implication draws on the potential inability of the market to deliver socially desirable automation technologies (technology which substantially increases overall productivity, and thereby creates new jobs in allied and varied fields). Government policies can aim at making labour have the competitive edge over automation in industries where automation is intended to merely substitute labour with capital. This can be done in two ways. 
First, we can increase the relative cost of capital thereby disincentivising automation. Reduction in tax deductions for interest, increased cost of acquiring automation technology, elimination of capital subsidies and so on are possible options in this regard. More explicit moves include implementation of 'robot taxes' repeatedly promoted by Bill Gates (Quartz 2017). However, this goes against the first principle of letting automation flow freely.

The second approach focuses on making labour have the competitive edge by implementing beneficial measures made available if firms opt for labour over automation. The Vice Chairman of the Niti Aayog has stated that we must dispense with capital subsidies, and it is time to focus on labour subsidies (Livemint 2017). Such subsidies reduce the cost of labour directly, while protecting wages from dropping below a statutory level. Combined with a push for generating jobs in emerging industries (such a manufacture of robots), routine-mechanical jobs - which most skilling training programs impart - can be reinstated by making labour have the competitive edge through subsidies.

\section{Other Concerns}

Firstly, automation has also been suspected of deskilling labour due to its polarising effect on jobs. Automation pushes existing mid- to low-skill workers into low- to un-skilled work and reduces the aggregate skill composition. Even when automation brings about a strong reinstatement effect, it has been observed that jobs created are menial in nature (ILO 2018c). Gamst (2015) notes that deskilling is a Marxian mode of societal control, wherein jobs are divided into discrete minute tasks which are to be repeatedly performed, not requiring any cognitive skills.

Secondly, availability of opportunity and attempts at skilling would not be sufficient. The oncoming digital wave is most likely to reflect and incorporate existing social hierarchies in India, with sociocultural forces shaping the capability of individuals to reap the benefits of technological advancements. This ranges from restriction of good formal education to upper echelons of the society to patriarchal forces restricting women to sell their labour online.

Thirdly, automation has become a tool for subverting democratic forces and progress. Strikes in 2011-2013 by workers at a Maruti plant in Gurgaon was quickly followed by accelerated automation (ILO 2018a). This highlights a clear impetus for automation of jobs to reduce the bargaining strength of labour. It has been argued that automobile manufacturers 'learnt' from the foregoing event and increased automation in their plants as well. The period revolving these 
strikes witnessed a $27 \%$ increase in purchase of industrial robots by the automobile industry (ibid.). COVID-19 has shown the relative elasticity of labour supply like never seen before and will surely add weight to this. Perverse incentives and socially undesirable impetuses must be kept under check.

\section{CONCLUSION}

While automation has the potential to bring in increases in efficiency and productivity, its effect on labour is polarising. Automation can hollow out mid-skill jobs, and as it is extremely difficult for mid-skill workers to move up the ladder, they are overwhelmingly pushed down into low-skill jobs, which can consequently widen socio-economic inequalities. The ongoing health crisis has accelerated the demand for automation. Millions of Indians who lost their jobs due to the crisis will be unable to re-enter at positions they occupied before the crisis as they will find that their jobs have been automated.

These two considerations together make it necessary for the State to intervene. However, such an intervention must respect the rights of the two key stakeholders involved, i.e. firms and workers. Firms should have the freedom to adopt automation technology they deem fit, while workers should be empowered to allow them to take their rightfully deserved share in the economic pie. This requires taking cognisance and implementation of three simultaneous systems. Firstly, labour's mobility should be increased by focusing on developing competencies that do not revolve around context-specific tasks. This requires the focus of policy makers as current skilling interventions focus on developing skills concerning routine tasks. Secondly, employment will have a dynamic nature going forward, with increasing contractualisation and digital platforms wherein workers can sell their labour to multiple employers. Such a situation calls for developing a social security mechanism which is detached not only from any specific employment but also the number of hours. And lastly, policymakers must make attempts to disincentivise firms from adopting automation technology that is aimed at substituting labour with capital.

\section{References}

Acemoglu, Daron, and David Autor. 2011. In Handbook of Labor Economics Vol 4, Part B, by David Card and Orley Ashenfelter, 1043-1171. Elsevier.

Acemoglu, Daron, and Pascual Restrepo. 2019. "Automation and New Tasks: How Technology Displaces and Reinstates Labour." Journal of Economic Perspectives Volume 33, Number 2 3-30. 
Acemoglu, Daron, and Pascual Restrepo. 2020. "The wrong kind of AI? Artificial intelligence and the future of labour demand." Cambridge Journal of Regions, Economy and Society 13 25-35.

BBC. 2020. June 4. Accessed June 15, 2020. https://www.bbc.com/news/world-asia-india-52905093.

Brynjolfsson, Erik, and Andrew McAfee. 2016. "Human Work in the Robotic Future: Policy for the Age of Automation." Foreign Affairs Vol. 95, No. 4 139-150.

BusinessLine. 2020. May 14. Accessed June 16, 2020. https://www.thehindubusinessline.com/news/cobotsexpected-to-play-increasing-role-in-post-covid-19-automation/article31579582.ece.

—. 2018. The Hindu Business Line. November 6. Accessed June 15, 2020. https://www.thehindubusinessline.com/opinion/columns/how-ai-will-transform-indias-jobscene/article25428983.ece.

CSLF. 2020. The Future of Industry and Employment: COVID-19 Effects Exacerbate the March of AI. Policy Brief, Centre for State and Local Finance.

Frey, Carl Benedikt. 2020. Opinion. April 21. Accessed June 17, 2020. https://www.ft.com/content/817228a282e1-11ea-b6e9-a94cffd1d9bf.

Gamst, Frederick C. 2015. "Work, Sociology of." International Encyclopedia of the Social \& Behavioral Sciences, 2nd edition, Volume 25 687-693.

ILO. 2018b. India Wage Report: Wage Policies for Decent Work and Inclusive Growth. Working Paper, ILO.

ILO. 2018a. Technological change and employment: Creative Destruction. ILO Asia Pacific Working Paper Series, ILO.

ILO. 2018c. The economics of artificial intelligence: Implications for the future of work. Research Paper, ILO.

Jaimovich, Nir, and Henry E. Siu. 2018. JOB POLARIZATION AND JOBLESS RECOVERIES. NBER Working Paper, Cambridge: NATIONAL BUREAU OF ECONOMIC RESEARCH.

Keynes, John Maynard. 1930. Economic Possibilities for our Grandchildren. http://www.econ.yale.edu/smith/econ116a/keynes1.pdf.

Kuriakose, Francis, and Deepa Iyer. 2018. Job Polarisation in India: Structural Causes and Policy Implications. December 28. https://papers.ssrn.com/sol3/papers.cfm?abstract_id=3347748.

Livemint. 2020. Covid-19 crisis will accelerate firms' automation plans: Report. May 15. Accessed June 17, 2020. https://www.livemint.com/industry/infotech/covid-19-crisis-will-accelerate-firms-automationplans-report-11589515863007.html.

—. 2017. NITI Aayog proposes scheme for saving jobs from automation. December 20. Accessed June 16, 2020. https://www.livemint.com/Politics/X02BkYjgt76mstRasNrEiI/NITI-Aayog-proposes-scheme-forsaving-jobs-from-automation.html.

Mani, Sunil. 2019. "Robot Apocalypse: How Will Automation Affect India's Manufacturing Industry?" Economic and Political Weekly Vol LIV no. 8, February 23: 40-48.

ManpowerGroup. 2020. India Talent Shortage. Demand survey, Manpower Grouup.

MSDE. n.d. PMKVY FAQ. Accessed June 16, 2020. http://pmkvyofficial.org/faq.php.

-. n.d. Skills Acquisition and Knowledge Awareness for Livelihood Promotion. Accessed June 15, 2020. https://www.msde.gov.in/assets/images/sankalp/note.pdf.

Muro, Mark. 2020. Technology \& Innovation: Economist. April 22. Accessed June 17, 2020. https://eiuperspectives.economist.com/technology-innovation/will-covid-19-pandemic-accelerateautomation.

NASSCOM. 2020. COVID-19: The Tipping Point for Automation. NASSCOM. 
Petropoulos, Georgios. 2018. "The Impact of Artifical Intelligence on Employment." In Work in the Digital Age: Challenges of the Fourth Industrial Revolution, by Max Neufeind, Jacqueline O'Reilly and Florian Ranft, 119-132. Rowman \& Littlefield.

Quartz. 2017. The robot that takes your job should pay taxes, says Bill Gates. February 17. Accessed June 16, 2020. https://qz.com/911968/bill-gates-the-robot-that-takes-your-job-should-pay-taxes/.

Rittel, Horst W. J., and Melvin M. Webber. 1973. "Dilemmas in a general theory of planning." Policy Sciences 4 (Springer) 155-169.

Sarkar, Sudipa. 2018. "Employment Change in Occupations in Urban India: Implications for Wage Inequality." Development and Change 00(0) 1-32.

Schumpeter, Joseph A. 1943. Capitalism, Socialism and Democracy. Taylor and Francis.

Tandem Research. 2018. Emerging technologies and the future of work in India. ILO Asia-Pacific Working Paper Series, ILO.

The Hindu. 2020. Hindu Data. May 7. Accessed June 15, 2020. https://www.thehindu.com/data/data-over-12crore-indians-lost-their-jobs-during-the-coronavirus-lockdown-in-april/article31520715.ece.

The iLabour Project. 2017. Oxford Internet Institute. Accessed June 16, 2020. http://ilabour.oii.ox.ac.uk/whereare-online-workers-located-the-international-division-of-digital-gig-work/.

The Wire. 2017. The Wire: Economy. January 19. Accessed June 17, 2020. https://thewire.in/economy/indiaglobal-productivity-slowdown.

Vashisht, Pankaj. 2017. Destruction or Polarization: Estimating the Impact of Technology on Jobs in Indian Manufacturing. Working Paper 334, ICRIER.

Vashisht, Pankaj, and Jay Dubey. 2018. Changing Task Contents of Jobs in India: Implications and Way Forward. ICREIR Working Paper 355.

World Bank. 2016. World Development Report 2016: Digital Dividends. Washington, DC: World Bank Group. 